\title{
A systematic review of ongoing clinical trials in optic pathway gliomas
}

\author{
Ciaran Scott Hill ${ }^{1,2}$ (D) $\cdot$ Sara Castro Devesa ${ }^{2} \cdot$ William Ince $^{4} \cdot$ Anouk Borg $^{3} \cdot$ Kristian Aquilina $^{1}$
}

Received: 22 April 2020 / Accepted: 3 June 2020 / Published online: 18 June 2020

(C) The Author(s) 2020

\begin{abstract}
Introduction Optic pathway gliomas (OPGs), also known as Visual Pathway Gliomas, are insidious, debilitating tumours. They are most commonly WHO grade 1 pilocytic astrocytomas and frequently occur in patients with neurofibromatosis type 1 . The location of OPGs within the optic pathway typically precludes complete resection or optimal radiation dosing, hence outcomes remain poor compared to many other low-grade gliomas. The aim of this systematic review was to formulate a comprehensive list of all current ongoing clinical trials that are specifically looking at clinical care of OPGs in order to identify trends in current research and provide an overview to guide future research efforts.

Methods This systematic review was conducted in line with the Preferred Reporting Items for Systematic Reviews and MetaAnalysis (PRISMA) guidelines. The Cochrane Controlled Register of Trials (CENTRAL) and ClinicalTrials.gov were searched. Inclusion and exclusion criteria were applied and final results were reviewed.

Results 501 clinical trials were identified with the search strategy. All were screened and eligible studies extracted and reviewed. This yielded 36 ongoing clinical trials, 27 of which were pharmacological agents in phase I-III. The remaining trials were a mixture of biological agents, radiation optimisation, diagnostic imaging, surgical intervention, and a social function analysis. Conclusion OPG is a complex multifaceted disease, and advances in care require ongoing research efforts across a spectrum of different research fields. This review provides an update on the current state of research in OPG and summarises ongoing trials.
\end{abstract}

Keywords Optic $\cdot$ Visual $\cdot$ Pathway $\cdot$ Glioma $\cdot$ Trial $\cdot$ Systematic review

$\begin{array}{ll}\text { Abbreviations } & \\ \text { CENTRAL } & \text { Cochrane Controlled Register of Trials } \\ \text { FDA } & \text { Food and Drug Administration } \\ \text { GOSH } & \text { Great Ormond Street Hospital } \\ \text { HDAC } & \text { Histone deacetylase } \\ \text { HGG } & \text { High-grade glioma } \\ \text { JPAs } & \text { Juvenile pilocytic astrocytomas } \\ \text { LGG } & \text { Low-grade glioma } \\ \text { LMIC } & \text { Low- or middle-income country }\end{array}$

Ciaran Scott Hill

ciaran.hill@nhs.net

1 Department of Neurosurgery, Great Ormond Street Hospital, London, UK

2 UCL Cancer Institute, University College London, London, UK

3 Department of Neurosurgery, Oxford University Hospital, Oxford, UK

4 Ipswich Hospital, East Suffolk and North Essex NHS Trust, Health Road, Ipswich IP45PD, UK

$\begin{array}{ll}\text { MRI } & \text { Magnetic resonance imaging } \\ \text { NCI } & \text { National Cancer Institute } \\ \text { NF } & \text { Neurofibromatosis } \\ \text { OPG } & \text { Optic pathway glioma } \\ \text { PXAs } & \text { Pilomyxoid astrocytomas } \\ \text { PRISMA } & \text { Preferred Reporting Items for } \\ & \text { Systematic Reviews and Meta-Analysis } \\ \text { RCT } & \text { Randomised controlled trial } \\ \text { WHO } & \text { World Health Organization } \\ \text { WHO ICTRP } & \text { World Health Organization } \\ & \text { International Clinical Trials } \\ & \text { Registry Platform }\end{array}$

\section{Introduction}

Optic pathway gliomas (OPGs), also known as visual pathway gliomas, are insidious, debilitating tumours that account for 3$5 \%$ of all paediatric brain tumours. They are a subtype of lowgrade glioma (LGG), most often World Health Organization 
(WHO) grade 1 juvenile pilocytic astrocytomas (JPAs), with a smaller proportion being pilomyxoid astrocytomas (PXAs) [1]. They are common in patients with neurofibromatosis type 1 (NF1), with up to $20 \%$ developing an OPG at a mean age of 4.5-5 years old [2]. OPGs most commonly arise at the chiasmatic-hypothalamic region but can arise anywhere along the optic pathway [3]. Their intimate relationship to the optic apparatus, hypothalamus, ventricular system and brain parenchyma can result in a variety of clinical sequelae including visual loss, endocrinopathies and hypothalamic dysfunction, developmental/neuropsychological disorders, hydrocephalus and focal neurological deficits. This complexity of symptomatology, and the close relationship to key structures make the treatment of OPG challenging. Unlike other JPAs, the location typically precludes complete surgical resection or optimum radiation dosing without incurring an often-unacceptable neurological cost. Furthermore, key aspects of their behaviour including their natural history and optimal management are incompletely understood. Tumour stabilisation, progression or regression can all occur unpredictably. OPG management is highly individualised. Many undergo a period of observation with serial imaging unless there is progressive growth or visual symptoms. Chemotherapy with a carboplatin/ vincristine 'Packer' regimen is often the first line, although alternatives such as the TPCV (thioguanine, procarbazine, lomustine, vincristine) are sometimes used, except in NF1 patients due to the risk of secondary leukaemia [4]. Radiotherapy is typically avoided in younger children due to risks of toxicity wherever possible [5], although it remains an option in the setting of refractory, progressive disease or where visual loss is occurring despite systemic therapy [6, 7]. The role of surgical biopsy and debulking surgery remains controversial $[8,9]$. OPGs require multidisciplinary care by neurosurgeons, neuro-oncologists, radiation oncologists, endocrinologists, ophthalmologists, pathology, neuropsychology, paediatricians, geneticists and a host of allied health professionals. This multifaceted care underlies the complexity of the disease. Advances in the understanding and treatment of OPG could come from a variety of sources, including novel or repurposed pharmacological agents, emerging biological agents and tumour vaccines, refinement of surgical approaches, diagnostic and therapeutic radiological developments or quality of lifefocussed research [10-16]. The aim of this systematic review was to formulate a comprehensive list of all current ongoing clinical trials that were specifically looking at a clinical care of OPGs in order to identify trends in current research and provide an overview of the field to guide future research efforts. This review includes trials that are registered, and in any stage of recruitment or analysis, but not yet published. A summary of each of the ongoing clinical trials will be presented to facilitate a rapid review of the field.

\section{Methods}

This systematic review was conducted in line with the Preferred Reporting Items for Systematic Reviews and Meta-Analysis (PRISMA) guidelines on April 10th, 2020 [17, 18]. Two clinical trial databases, the Cochrane Controlled Register of Trials (CENTRAL) and ClinicalTrials.gov, were searched. The search terms used to identify clinical trials were as follows: '(optic OR pathway OR visual OR opg OR chiasm OR midline OR hypothalamic OR hypothalamus OR neurofibromatosis OR NF1 OR pediatric OR paediatric) AND (glioma OR pilocytic OR astrocytoma OR pilomyxoid)'. Trials older than 2010 were excluded. Trial titles and abstracts were reviewed by two of the authors. Titles with no English language translation available, and duplicates, were removed. Exclusion criteria were applied; these included titles that were not related to OPG or to trials that would not include OPG as a subgroup based on their inclusion/exclusion criteria. Already-published studies were excluded; these articles were reviewed to ensure that the publications were final and complete, and not an interim analysis or partial publication, with further publication of trial results expected. Studies that had been withdrawn, abandoned or not updated in 3 years or more were also excluded. For identified trials where there had been no recent clinical trial update (in print or online) for $>3$ years, contact was made with the principal investigator of the trial to establish progress and assess if the trial was still running. Two authors ( $\mathrm{CSH}$ and $\mathrm{AB}$ ) performed the search strategy independently and reviewed the final papers separately. Any conflicting findings were reviewed (by $\mathrm{CSH}, \mathrm{AB}$ and WI) and a consensus agreed.

\section{Results}

Five hundred one clinical trials were identified with the search strategy described. After initial exclusions, 292 were screened. Thirty-six eligible studies were included in the final analysis. The identification, screening, eligibility and inclusion were conducted according to PRISMA guidelines. The strategy is summarised in Fig. 1.

After application of the PRISMA search strategy, we included 36 clinical trials in our final analysis.

A detailed summary of the stratified clinical trials included in the review is presented in Table 1.

Out of the 36 clinical trials assessed, 27 were pharmacological studies. There was one phase 0 trial, 8 phase 0/I drug trials, 7 mixed phase I and phase II, 9 phase II, and 2 phase III trials. There were 2 trials focussed on biological agents, 2 based on optimising radiation therapy, 2 on diagnostic neuroimaging, one on imaging-guided thermotherapy, one on genetic testing and one on social functioning. 
Fig. 1 PRISMA process summary. This figure demonstrates article inclusion and exclusion across the various stages of review
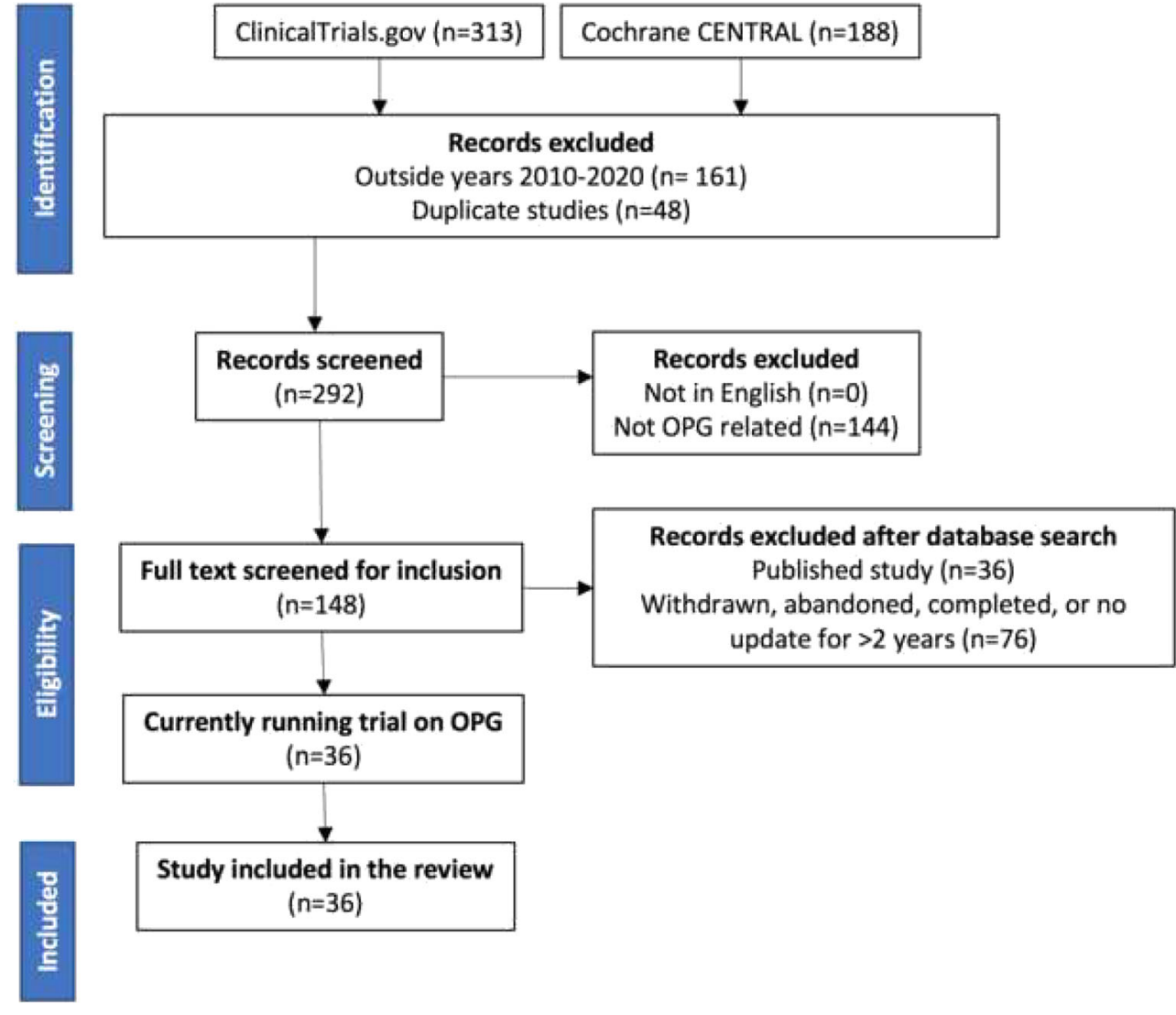

\section{Discussion}

Systematically reviewing the ongoing clinical trials is important to update clinicians on potential new therapies, avoid duplication of research and identify research trends and developing areas of study to stimulate new investigation. As might be expected, the main focus of ongoing research studies in OPG is related to pharmacological agents. Twenty-seven out of the 36 identified research trials were drug trials. Such investigations are necessary to establish safety and efficacy of all new drugs and are essential to determine if these agents should be adopted or discarded. Many of the new agents were related to the BRAF/MEK/ERK or RAS pathways. A summary of the pharmacological agents under investigation is presented in Table 2.

There were 5 ongoing trials into the same pharmacological agent selumetinib, and 2 looking at trametinib; this raises a question as to whether a collaborative approach would allow data sharing and ensure a common data element and consensus reporting. The included trials were dominated by North American centres and pharmaceutical companies. We did not identify any trials run from a low- or middle-income country (LMIC) despite reports that up to $80 \%$ of all paediatric cancer patients occur in these countries. Potential reasons for the lack of clinical trials in LMIC include a lack of specialised centres, equipment and staff, and a lower priority of cancer for healthcare planning strategies [19-21]. There were a small number of trials looking at non-pharmacological diagnostics, therapeutics and assessment social functioning relating to OPG. These are summarised in Table 3.

\section{Pending trials}

The authors are aware of a further relevant clinical trial that is yet to start, the LOw Grade Glioma In Children (LOGGIC) study. LOGGIC will compare the effect of standard chemotherapy versus MEK inhibitor (trametinib) as first-line agents in paediatric low-grade glioma. The outcome measures will include a child's quality of life, including visual and neurological function. The LOGGIC trial will be run by the European Society for Paediatric Oncology (SIOPE). As with any emerging field, this is likely to be just one of several trials not yet registered on public databases.

\section{Unanswered questions}

This systematic review highlights the dominant pharmacologic-centric nature of current OPG clinical trial research. There are several important areas of OPG care that remain clouded in uncertainty and controversy and are not currently being addressed by the ongoing clinical trials we identified in this study. A key outstanding question is 


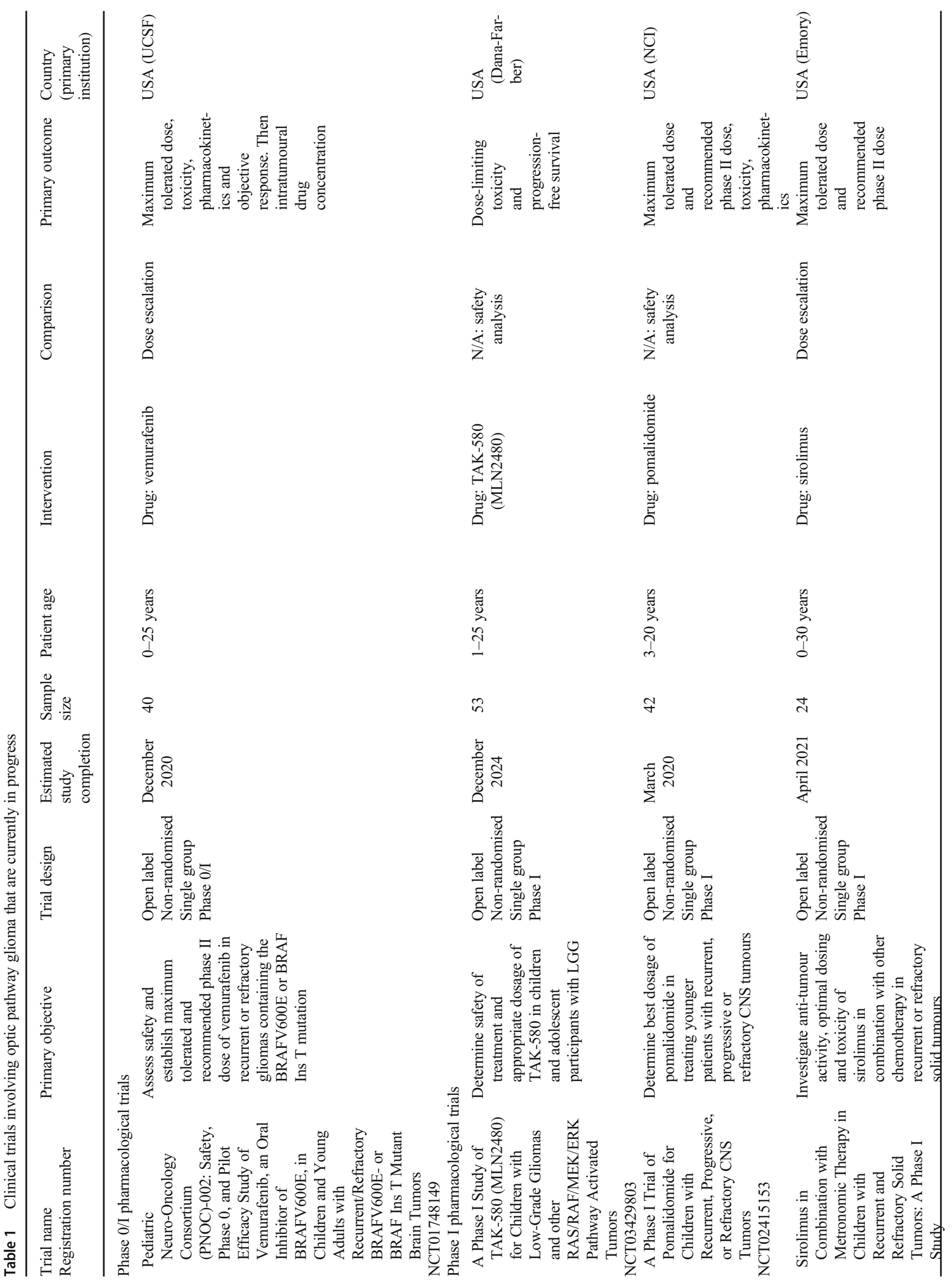




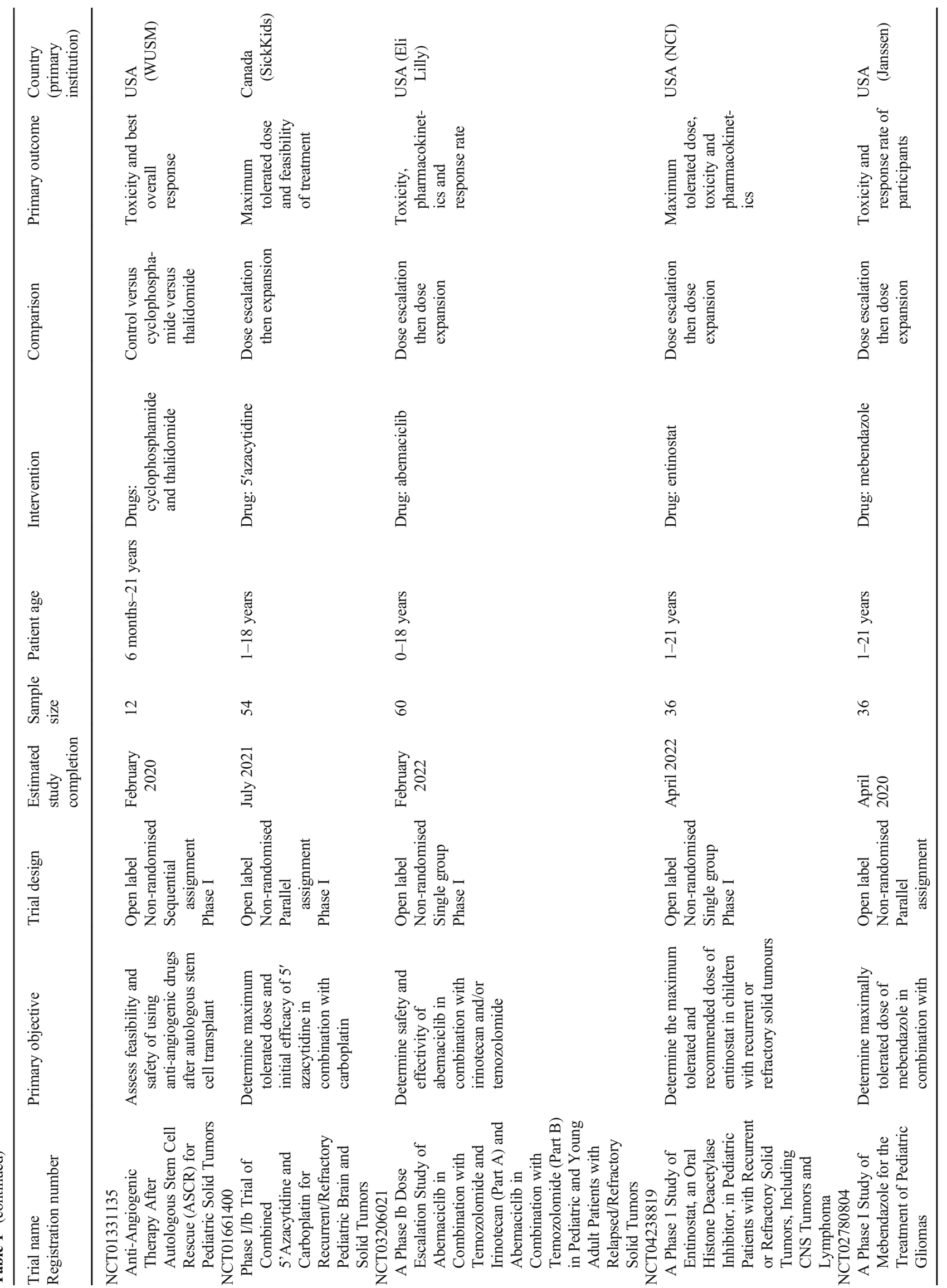




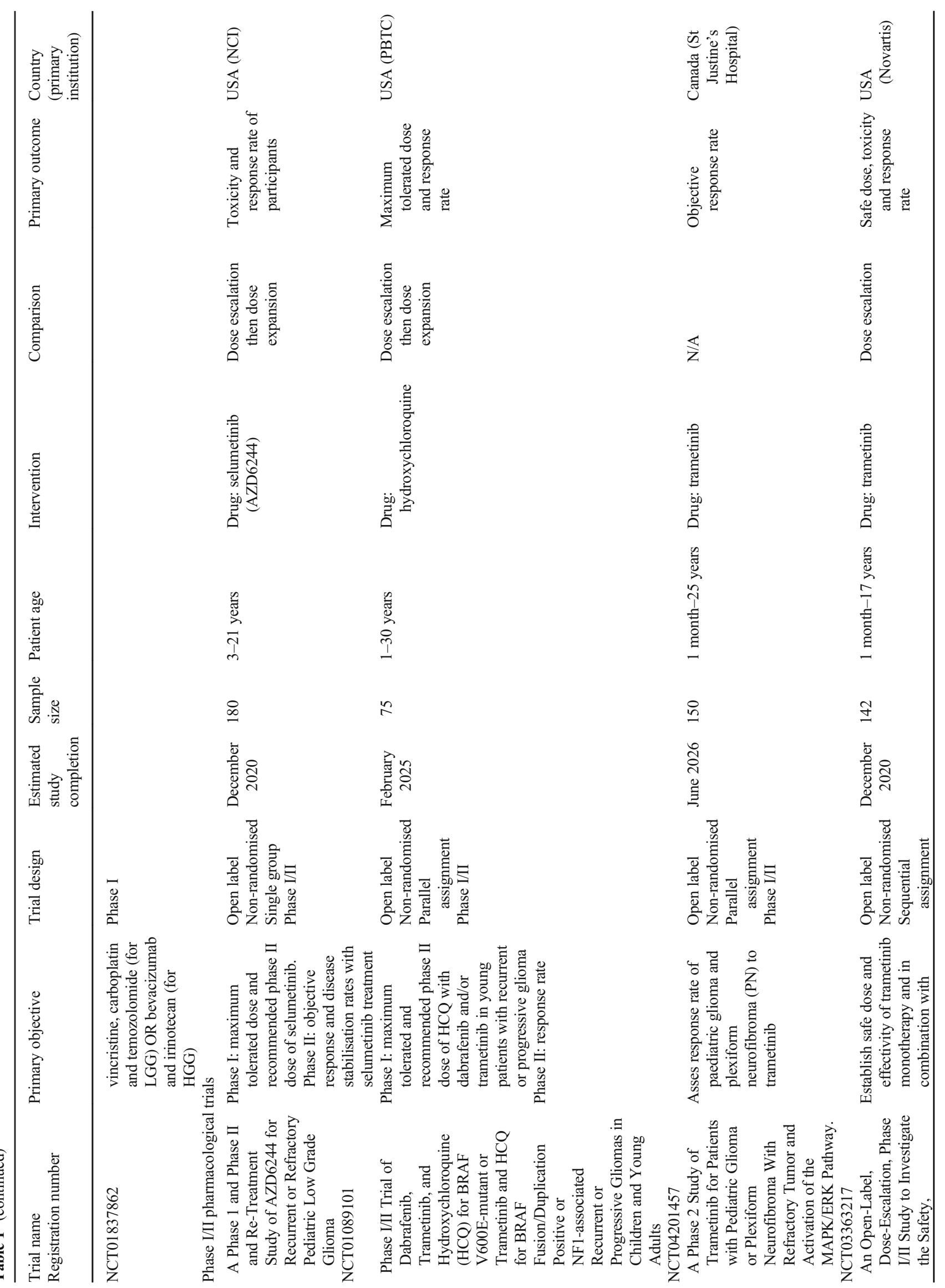




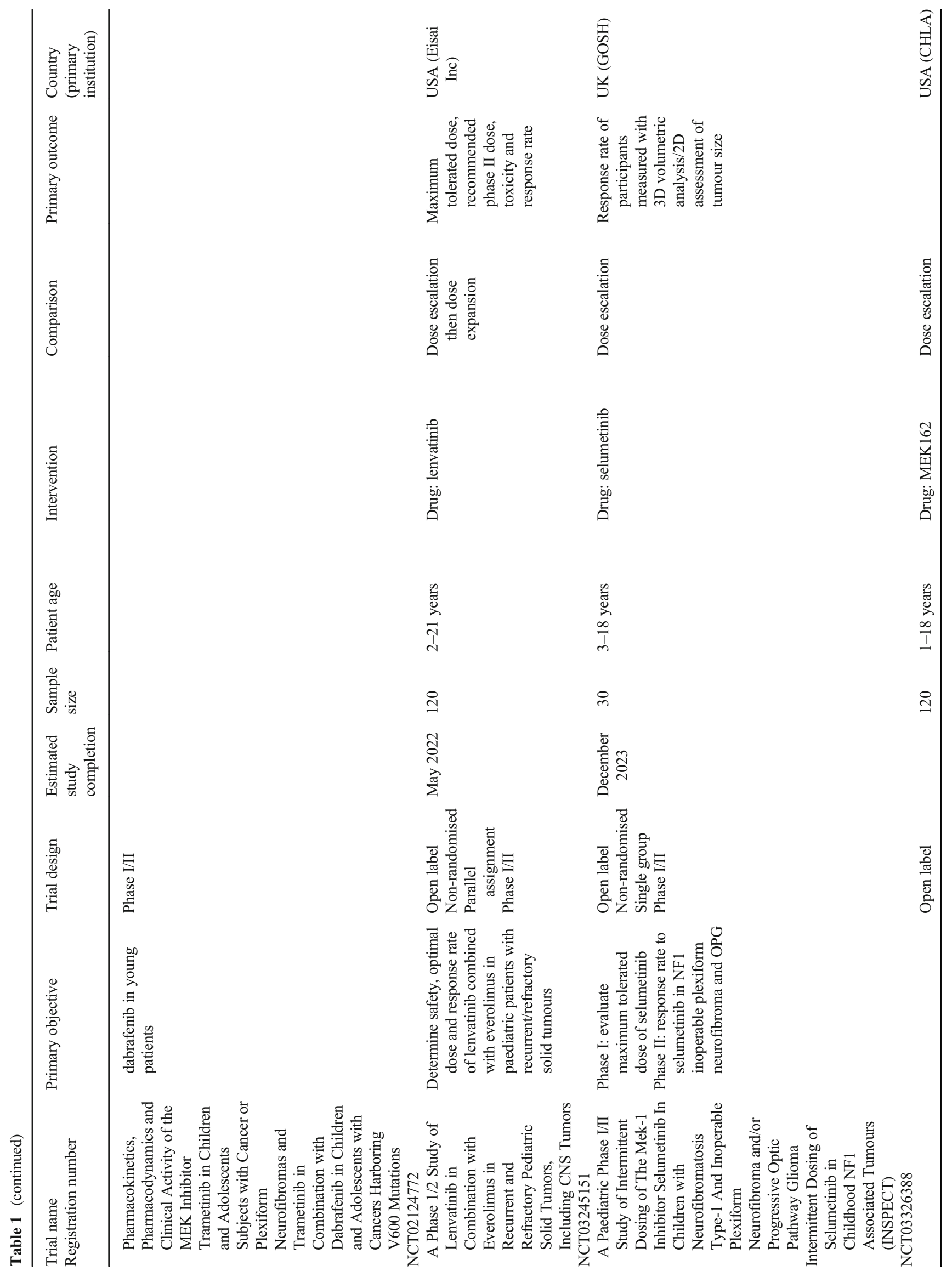




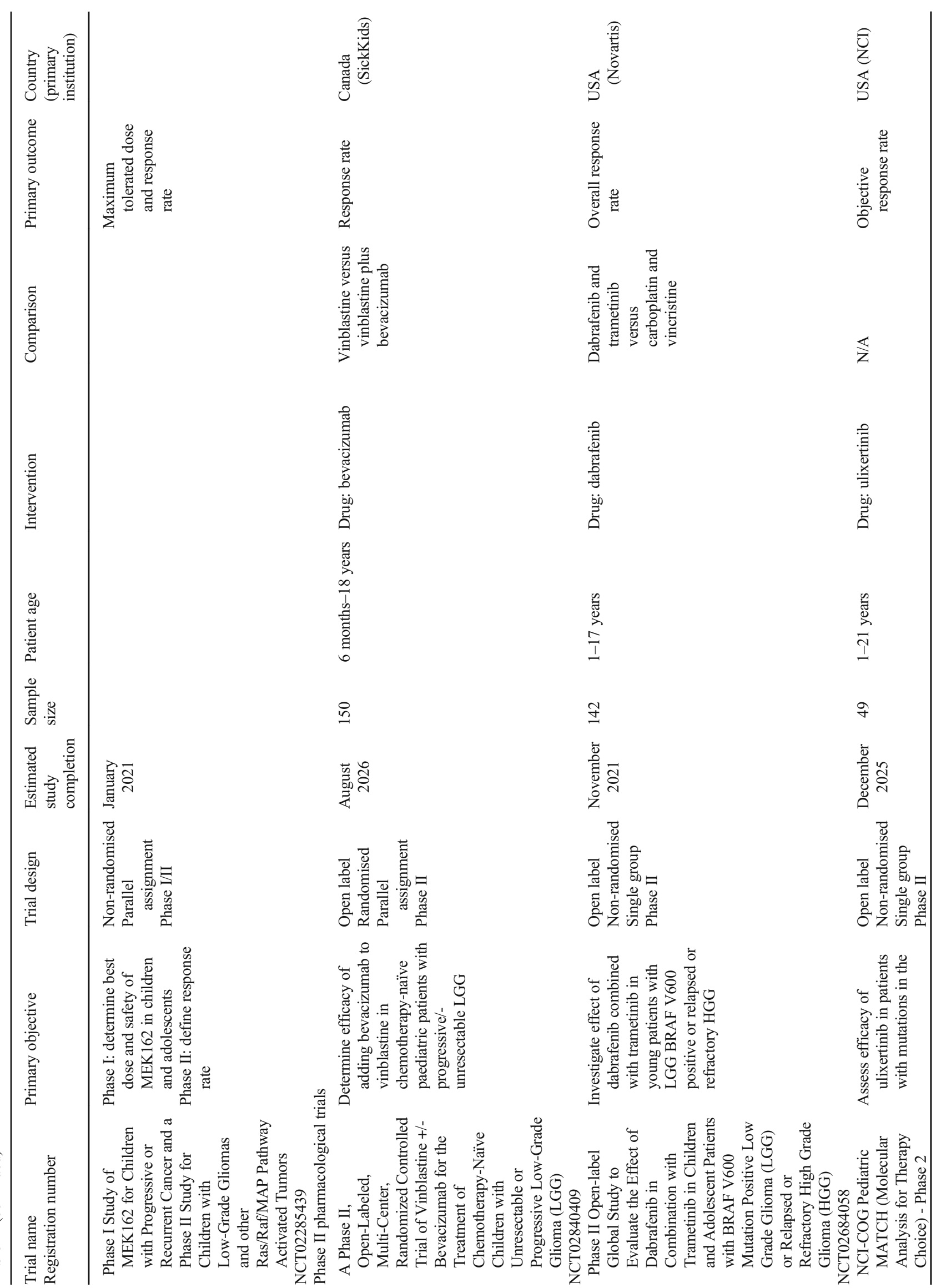




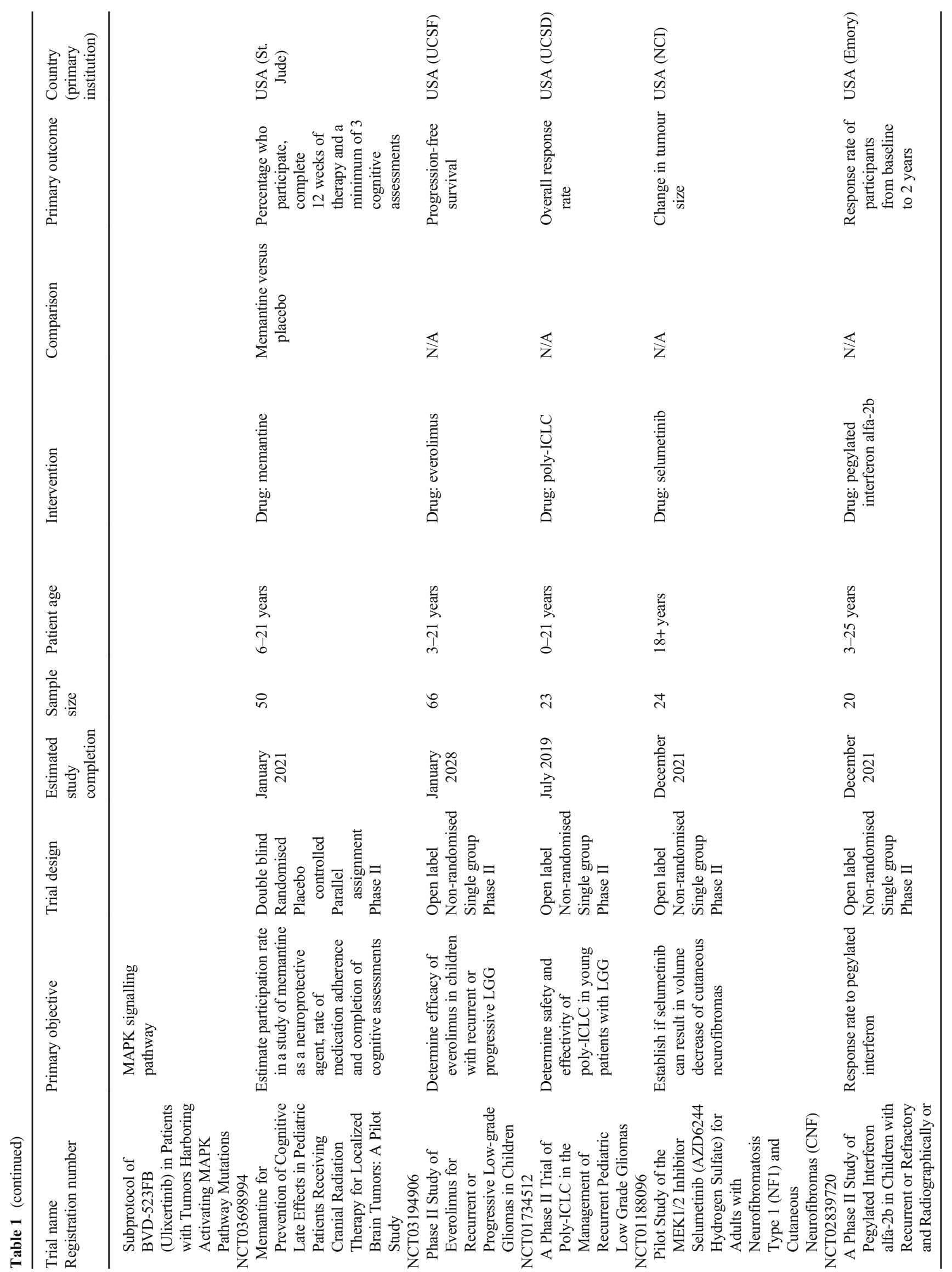




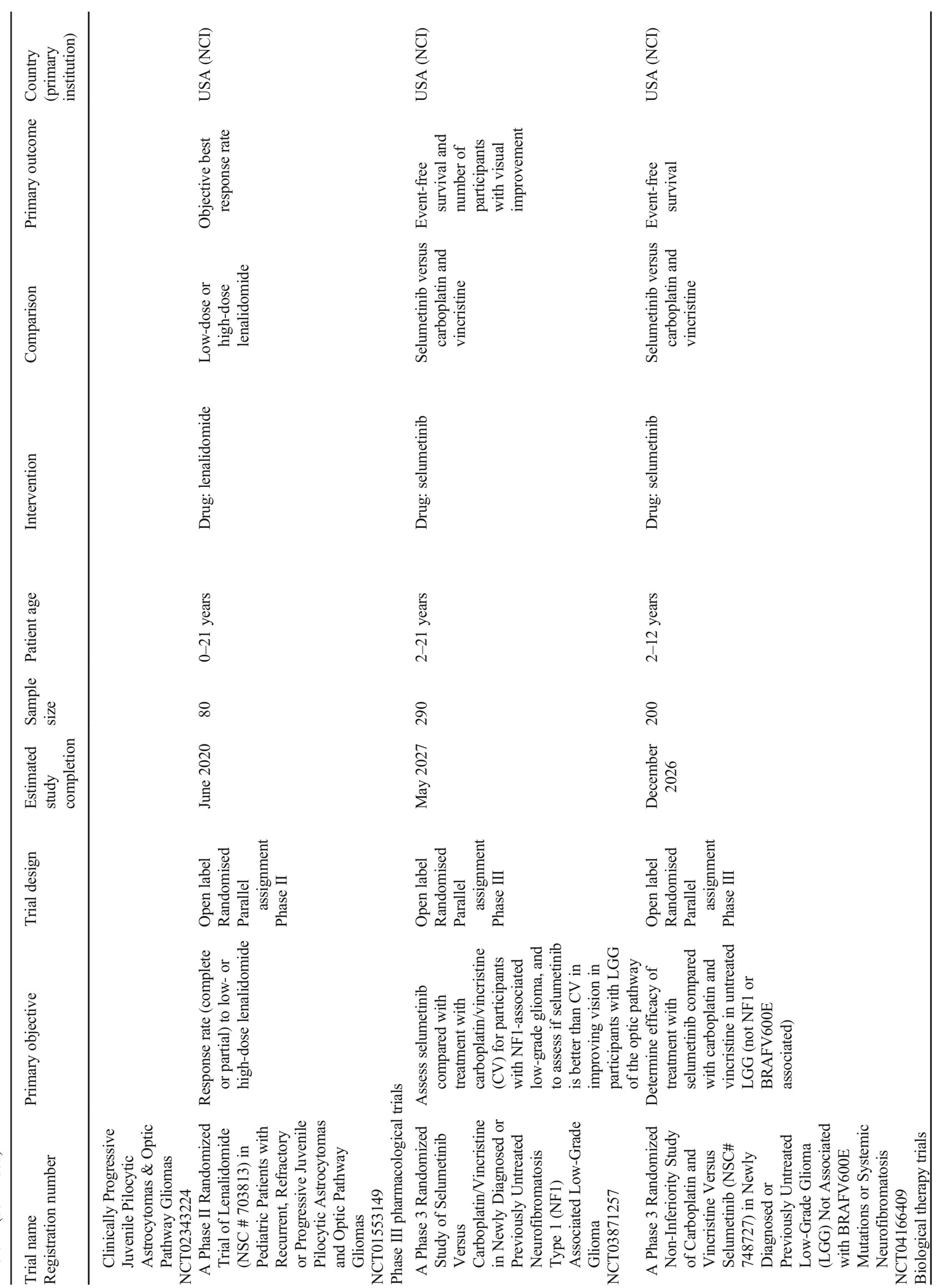




\begin{tabular}{|c|c|c|c|c|c|}
\hline 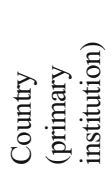 & 离 & 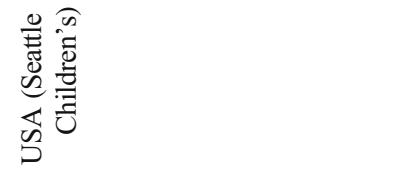 & 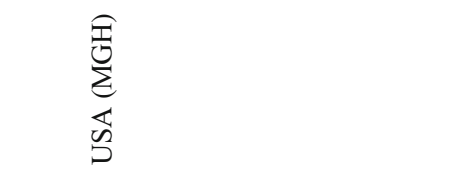 & 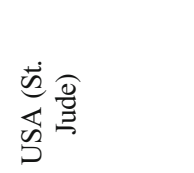 & \\
\hline & 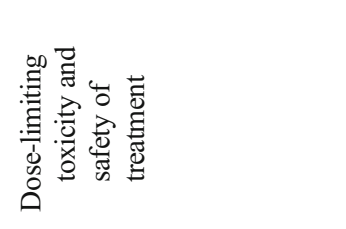 & 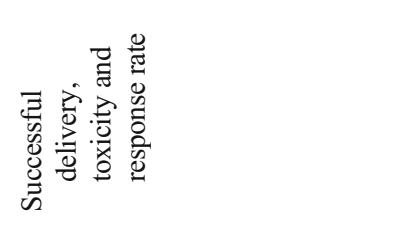 & 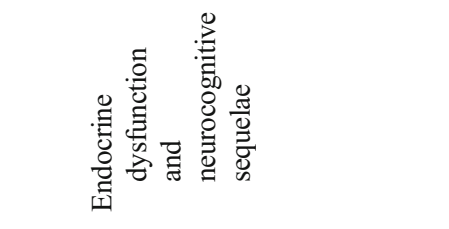 & 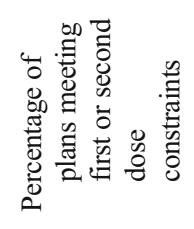 & 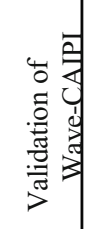 \\
\hline & 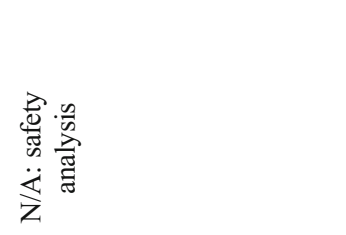 & 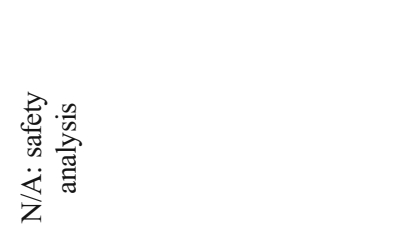 & 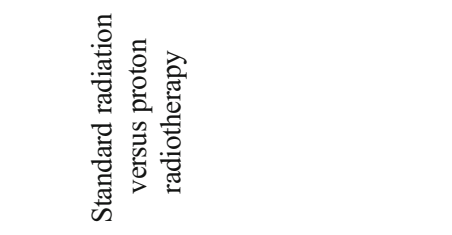 & $\overleftrightarrow{\mathrm{z}}$ & $\overleftrightarrow{Z}$ \\
\hline : & 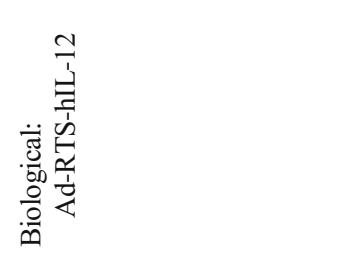 & 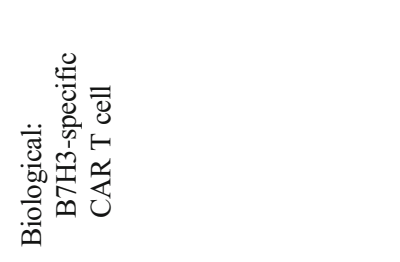 & 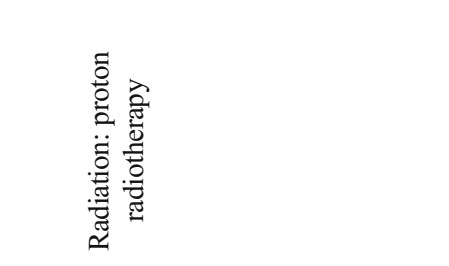 & 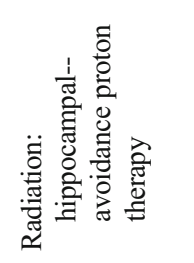 & \\
\hline 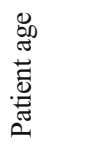 & 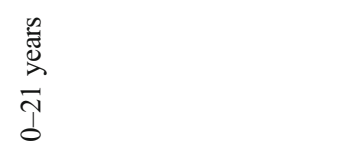 & 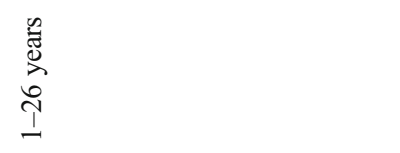 & 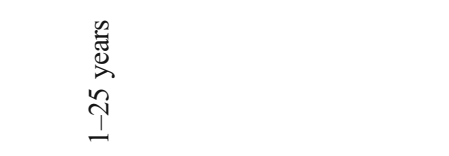 & 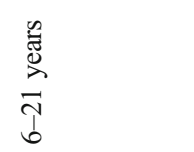 & $\bar{z}$ \\
\hline & $\stackrel{\sim}{\sim}$ & 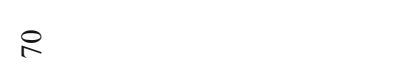 & 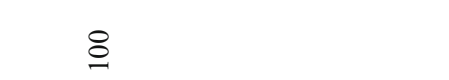 & $\stackrel{\nabla}{ }$ & ి్ల \\
\hline 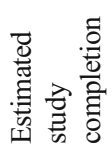 & 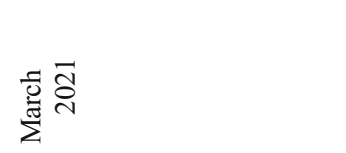 & 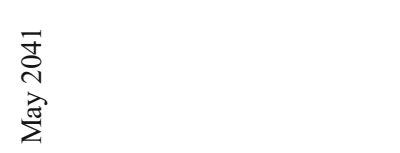 & 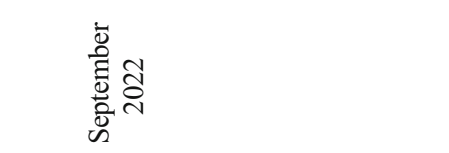 & 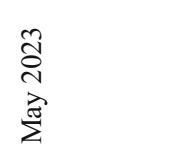 & 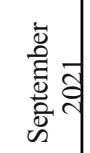 \\
\hline 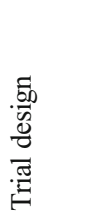 & 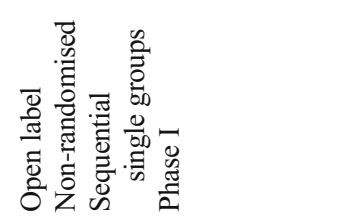 & 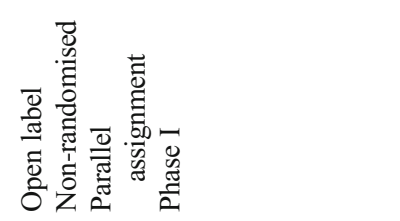 & 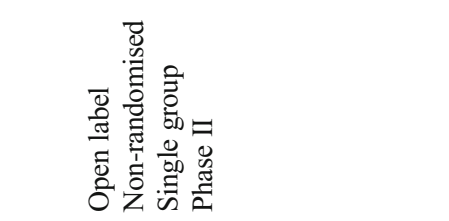 & 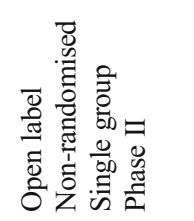 & 这 \\
\hline 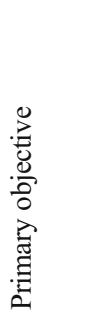 & 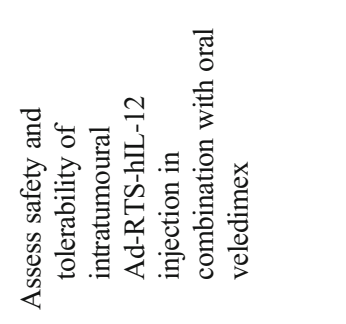 & 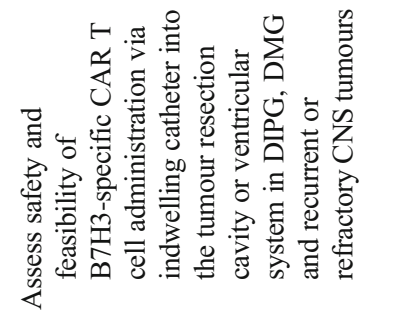 & 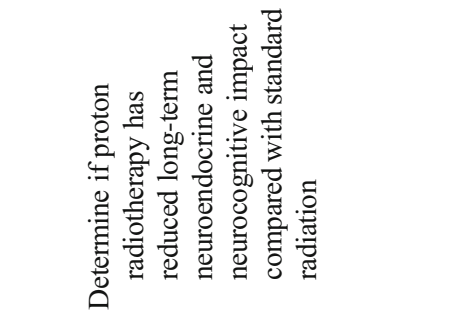 & 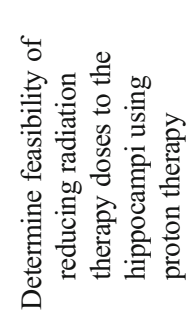 & 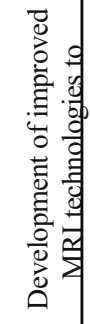 \\
\hline 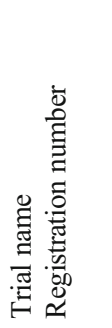 & 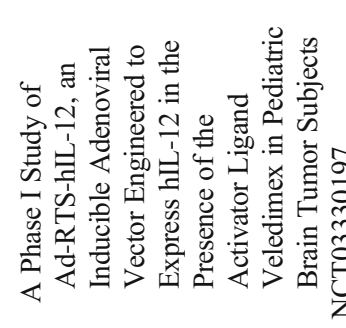 & 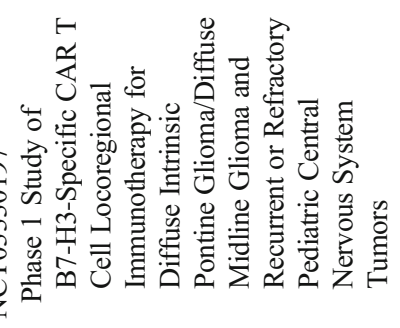 & 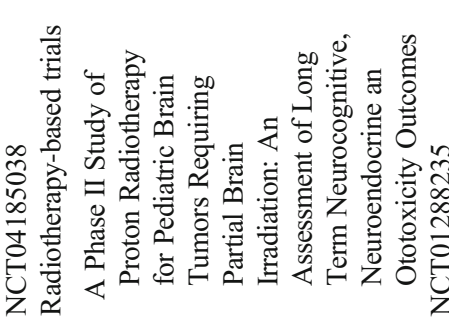 & 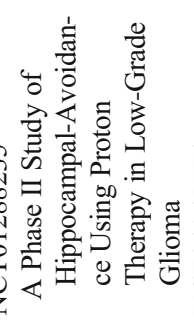 & 另 \\
\hline
\end{tabular}




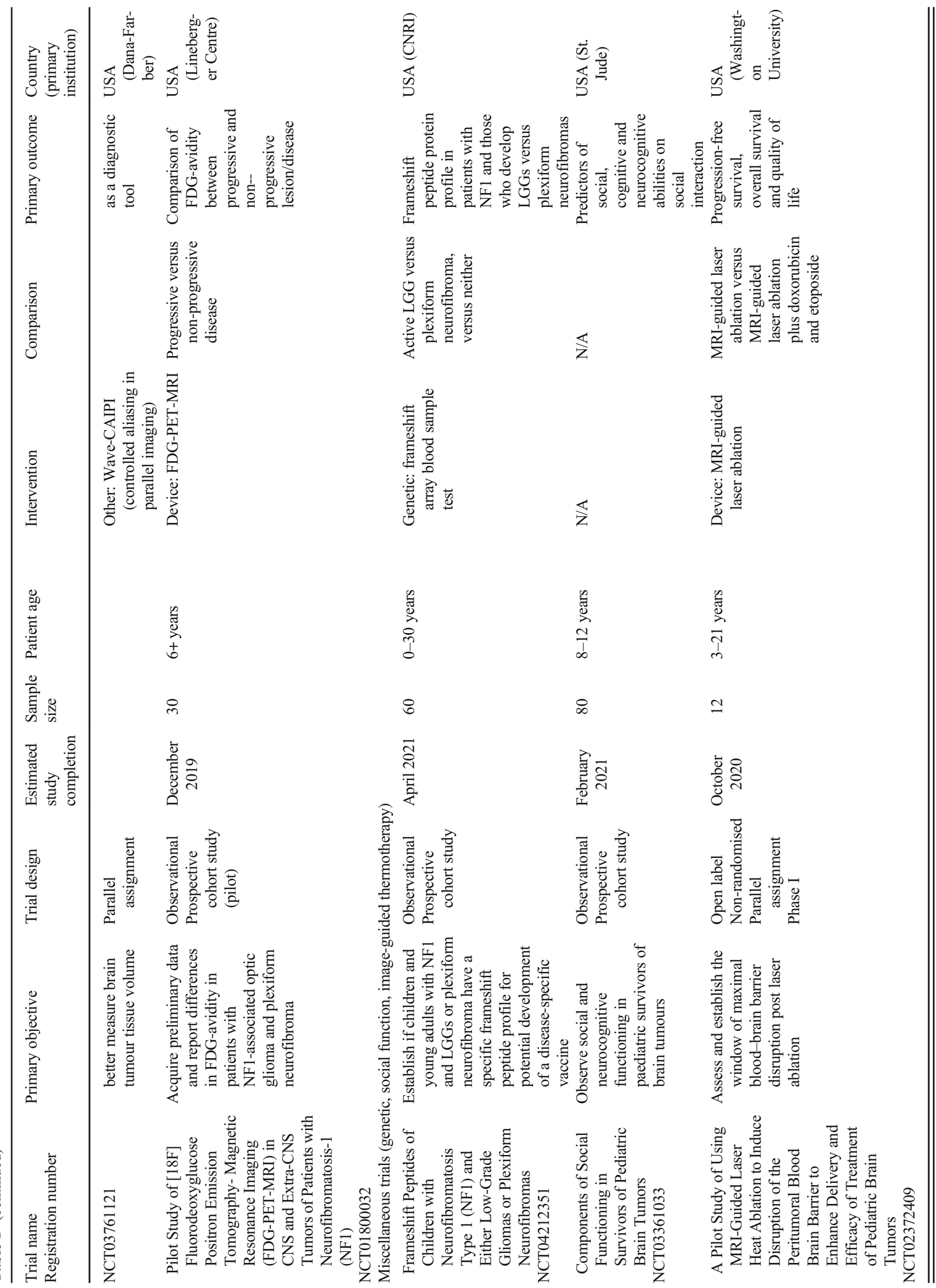


Table 2 Pharmacological agents under investigation as potential therapies in optic pathway gliomas

Drug/intervention

Proposed mechanism of action

BRAF/MEK/ERK pathway targeting agents

The MAPK/ERK signalling pathway is a key regulator of biological growth, proliferation and differentiation. The MAPK/ERK pathway is often upregulated in a variety of tumour types including glioma. The BRAFV600E mutation leads to constitutive overactivation of BRAF which is a driver of tumourigenesis in BRAFV600E mutant low-grade gliomas [27-29].

Vemurafenib/dabrafenib Selective type 1 B-Raf competitive small molecule enzyme inhibitors. Selectively recognises and binds the ATP-binding domain of BRAFV600E mutants. This interrupts the B-Raf/MEK step on the B-Raf/MEK/ERK pathway that is a driver of tumourigenesis in BRAFV600E mutant LGGs. Vemurafenib has shown some promise in the treatment for BRAFV600E mutant LGGs [30].

Tak580

Oral pan-Raf kinase inhibitor. A single-patient study demonstrated apparently good tolerance in a patient with refractory LGG ahead of a larger planned clinical trial [31].

Ulixertinib An ERK1/2 inhibitor. Blocking ERK-mediated signal transduction may inhibit ERK-dependent tumour cell proliferation and survival.

RAS pathway targeting agents

The RAS/MAPK pathway is important in the control of cancer cell growth and proliferation. The NF1 product neurofibromin functions as a negative regulator of RAS activity. RAS overactivity in patients with NF1 drives tumourigenesis. The MEK pathway is hyperactivated in NF1-deficient astrocytes and this drives NF1-associated optic glioma growth. Hence, the rationale for sustained MEK pharmacologic blockade in attenuating NF1-deficient astrocytes and NF1 optic glioma volume and proliferation [32]. The development of agents that target RAS signalling and associated pathways implicated in the pathogenesis of neurofibromas has led to clinical trials of various new pharmacological agents.

Selumetinib/trametinib Selective MEK inhibitor. A phase I study assessing selumetinib dose tolerance and pharmacokinetics in NF1-related plexiform neurofibromas was conducted by Dombi et al. who demonstrated benefit in inoperable plexiform neurofibromas without excess toxicity [33]. A further phase II study in relapsed LLG that included OPG showed sustained partial therapeutic response [34].

MEK162 (binimetinib) Orally available inhibitor of MAPK2.

Anti-angiogenic agents

Bevacizumab

A humanised monoclonal antibody directed against VEGF, this inhibition leads to a reduction in microvascular growth of tumour blood vessels and thus limits the blood supply to tumour tissues. There are several reports of the benefit of anti-VEGF drugs in uncontrolled case series [35-38].

Lenvatinib

Multireceptor TK inhibitor with preferential anti-angiogenic capacity. It inhibits VEGF receptor family 1-3, FGFR family 1-4, PDGFRa, TK receptor and RET. As a result, it may modulate the tumour microenvironment and anti-tumour responses [39].

Thalidomide

An anti-angiogenic agent. The mechanism of anti-angiogenic action is not fully known [40]. Its use has been investigated in the care of high-grade glioma [41].

Lenalidomide

An analogue of the anti-angiogenic agent thalidomide. It has demonstrated a significant anti-tumour activity in patients with multiple myeloma and myelodysplastic syndrome. Phase I studies in adults and children demonstrated tolerability but was associated with thromboembolic events and myelosuppression [42-44]. Antagonistically, the use of lenalidomide has been associated with secondary primary high-grade astrocytoma development in multiple myeloma [45].

Pomalidomide

An analogue of the anti-angiogenic agent thalidomide. It failed to demonstrate benefit in a phase II clinical study as monotherapy for children and young adults with recurrent or progressive primary brain tumours [46].

Miscellaneous pharmacological agents

Mebendazole

Methyl N-[6-(benzoyl)-1H-benzimidazol-2-yl] carbamate. A benzimidazole anti-helminthic used to treat a variety of worm infections and for echinococcosis (hydatid disease). Mebendazole binds to tubulin subunits preventing polymerisation. Tubulin is a key molecule in cell division and has been proposed as an anti-cancer target. Other potential targets of mebendazole include the Hh signalling pathway, and angiogenesis through VEGF inhibition [47]. Repurposing of mebendazole has been suggested in various tumours and it has been previously trialled in preclinical models of glioblastoma with some success [48-50].

Entinostat

Entinostat is a synthetic benzamide HDAC type 1 and III inhibitor. It is orally bioactive. Its proposed mode of action is to regulate chromatin structure and through histone deacetylation control epigenetic gene transcription. Other mechanisms of effect may include induction of reactive oxygen species leading to mitochondrial damage and inducing cell cycle arrest [51, 52].

Pegylated interferon alfa- $2 b$

Pegylated interferon $\alpha-2 b$ is a member of the interferon family; these are glycoproteins with anti-cytokine effects that have documented immune-modulating and anti-proliferative effects. One phase II study is examining the effect of pegylated interferon alfa- $2 \mathrm{~b}$ in a child with recurrent or refractory/progressive JPA and OPG in children. Studies have shown that interferon alfa-2b is tolerable and may delay progression in DIPG [53].

Abemaciclib

Reversible small molecular CDK inhibitor. Some gliomas have been shown to overexpresses cyclin D1, which in turn increases activity of CDK4 and CDK6; these enzymes phosphorylate (and therefore deactivate) retinoblastoma protein. Deactivating retinoblastoma protein leads to excess cellular growth by loss of cell cycle control at the G1 to S phases. Abemaciclib has demonstrated some effect in slowing growth in preclinical glioblastoma models [54]. 
Table 2 (continued)

\begin{tabular}{|c|c|}
\hline Drug/intervention & Proposed mechanism of action \\
\hline Hydroxychloroquine & Various possibilities including modulation of autophagy, cellular metabolism or direct chemotoxic effects [55]. \\
\hline Sirolimus/everolimus & $\begin{array}{l}\text { First- and second-generation mTOR inhibitors. The mTOR pathway is important in control of cellular growth. These drugs } \\
\text { have been trialled in giant cell astrocytomas as part of tuberous sclerosis complex, and everolimus is currently used in } \\
\text { some cases that are not amenable to surgical resection }[56,57] \text {. }\end{array}$ \\
\hline Memantine & An NMDAR1 antagonist thought to have anti-tumour and neuroprotective effects. It has been studied in glioblastoma. \\
\hline Poly-ICLC & $\begin{array}{l}\text { A synthetic double-stranded RNA complex. Poly-ICLC is a ligand for toll-like receptor-3 and MDA-5 that can activate } \\
\text { immune cells (including dendritic cells and natural killer cells) and therefore act as a stimulating immunomodulating } \\
\text { agent to induce tumour cell killing [58]. }\end{array}$ \\
\hline Cyclophosphamide & $\begin{array}{l}\text { A chemotherapeutic agent. Cyclophosphamide forms an active metabolite phosphoramide mustard in cells with low levels } \\
\text { of ALDH, as is the case in some tumour cells. The phosphoramide mustard forms irreversible DNA interstrand cross-links } \\
\text { that trigger tumour cell apoptosis. It has been shown to enhance glioma virotherapy by inhibiting innate immune } \\
\text { responses [59-61]. }\end{array}$ \\
\hline 5'Azacytidine & $\begin{array}{l}\text { An inhibitor of DNA methylation. This may be beneficial in LGGs with hypermethylation as part of their genetic phenotype } \\
\text { [62]. }\end{array}$ \\
\hline
\end{tabular}

$B R A F$ rapidly accelerated fibrosarcoma gene $\mathrm{B}(\mathrm{B}-\mathrm{Raf}=$ protein), $C D K$ cyclin-dependent kinase, $D I P G$ diffuse intrinsic pontine glioma, $E R K$ extracellular signal-regulated kinases, FGFR fibroblast growth factor receptor, HDAC histone deacetylase, $H h$ hedgehog, $L G G$ low-grade glioma, $M A P K$ selective mitogen-activated protein kinase, $M E K$ selective mitogen-activated protein kinase, $m T O R$ mammalian target of rapamycin, NF1 neurofibromatosis 1, NMDAR $N$-methyl-D-aspartate receptor, $O P G$ optic pathway glioma, $P D G F R a$ platelet-derived growth factor receptor alpha, $R E T$ rearranged during transfection receptor, Poly-ICLC polyinosinic-polycytidylic acid-poly-L-lysine carboxymethylcellulose, $T K$ tyrosine kinase, $V E G F$ vascular endothelial growth factor

regarding the natural history of OPG and how we can predict outcomes. We have a paucity of understanding of the natural history of OPGs, and we lack tools to predict their clinical course and long-term outcomes. Furthermore, it is controversial which outcome measure should be used. Commonly used oncological outcome measures such as overall survival and (radiological) progression-free survival may not be the most appropriate for the study of OPGs; alternatives include visual function, endocrine/ hypothalamic dysfunction and quality-of-life measures. While one trial identified in this review relates to social functioning, this remains a poorly examined area. Hypothalamic dysfunction is a key component of the OPG disease that is often neglected in clinical studies and can be challenging to quantify. The hypothalamic consequences of existing and emerging therapies need examination. Questions remain regarding the optimal therapeutic management. Although general consensus statements exist, there remains uncertainty around the optimal surgical strategy. The timing and nature of the surgical approaches to OPGs have not been subjected to rigorous trial data. Surgical options include biopsy, partial/subtotal resection and radical resection [13]. Furthermore, the optimal timing of chemotherapy/radiotherapy initiation and the influence this has on overall outcomes are not fully known. The focus of current research, including all trials identified in this study, is on recurrent/refractory OPGs rather than new diagnosis. The long-term efficacy of various treatments for newly diagnosed OPGs is unknown. Optic pathway gliomas are typically treated as a single disease. However, it may be important to stratify and subclassify based on factors such as age (infantile versus juvenile) and based on molecular/genetic subtyping. An example of this is stratification into syndromic/NF1-related and non-syndromic/ non-NF1-related OPGs. These patients have different anatomical predilections, their natural histories can vary and the optimal therapies may be different [22-24].

\section{Limitations}

We found few trials that were specifically focussed on OPGs as a distinct tumour subtype. As OPGs are a subset of LGG, they may be bundled into trials under umbrella terms like 'LGG' or 'glioma' or 'JPA/PXA'. We not only developed a search strategy aimed at capturing trials that had specific reference to OPG (with the search terms; optic/visual/pathway/chiasm/midline/ hypothalamus/hypothalamic) but also included terms to capture trials that may include OPGs without specific reference to them, e.g. by using terms (Neurofibromatosis/NF1/paediatric/paediatric) combined with generic blanket terms (glioma/ astrocytoma/pilocytic/pilomyxoid). Where appropriate, we screened the trial protocols and inclusion/exclusion criteria to determine if OPGs might be included in the trials. As with any systematic review, there is always a risk that our search strategy missed a relevant trial. This risk is higher with a disease like OPG that is a subcategory of a wider disease. In order to try and minimise this danger, we used a reproducible search strategy that conformed to PRISMA guidelines. We elected to include all trials that could recruit OPGs; however, the vast majority are not focussed on OPGs but on LGG in general. We ensured that 
Table 3 Ongoing non-pharmacological trials related to optic pathway glioma

Object of investigation
Non-pharmacological therapeutics
Ad-RTS-hIL-12

Ad-RTS-hIL-12

B7-H3-specific CAR T cell

Proton radiotherapy
MRI-guided laser heat ablation

Frameshift peptides

Imaging diagnostics

Fast paediatric imaging with Wave-CAIPI

\author{
Positron emission \\ tomography
}

Psychological assessment

Social functioning
Explanation

An inducible adenoviral (Ad) vector encoding human pro-inflammatory cytokine interleukin-12 (hIL-12) p70 transgene. This is under the transcriptional control of the RheoSwitch Therapeutic System (RTS) and can be activated by administration of the proprietary diacylhydrazine-based activator ligand veledimex. Activation and transcription of IL-12 is proposed to have immunomodulating and anti-neoplastic activities [63].

Chimeric antigen receptor (CAR) T cell therapy has emerged as a potential treatment in a range of cancers. CAR T cells are synthetic molecules composed of antibody binding domains connected to $\mathrm{T}$ cell activating domains and co-stimulatory domains. This allows highly specific tumour antigen recognition and subsequent $\mathrm{T}$ cell activation. The B7-H3 antigen is a transmembrane protein that is overexpressed in a range of tumours, and so manufacture of CAR T cells targeted to $\mathrm{B} 7-\mathrm{H} 3$ may be effective in a range of solid cancers including glioma $[64,65]$.

There were two studies identified that relate to proton radiotherapy. Protons are high-energy subatomic particles that when accelerated can be used to deliver focussed ionising radiation to a tumour in order to damage its DNA - killing tumour cells and inhibiting growth.

One study is focussed on assessing long-term neurocognitive, neuroendocrine and ototoxicity outcomes. The other is assessing the capacity of proton beam therapy to successfully avoid hippocampal irradiation in LGG.

MRI-guided laser ablation (MLA) is a minimally invasive laser surgery technique that involves a scalp incision and a small burr hole through which a laser probe is inserted into the centre of a brain tumour under MRI guidance. The probe delivers hyperthermic ablation to the tumour which can destroy tumour tissue and also disrupts the tumour blood-brain barrier potentially enhancing the delivery of chemotherapeutic agents [66].

A frameshift mutation is caused by insertion of deletion of a nucleotide sequence into DNA that creates a 'frameshift' as it is not a multiple of 3 (the number of nucleotides in a codon). This frameshift alters the whole DNA sequence and results in an altered gene and subsequent protein product. These 'frameshift peptides' can act as new epitopes that are potential targets for tumour vaccines. The study NCT04212351 proposes to determine if NF1-associated LGGs have a specific frameshift peptide protein profile that could be targeted with a specific vaccine [67].

Wave-CAIPI (controlled aliasing in parallel imaging) is an MRI-based technology that is faster than conventional MRI imaging. Parallel imaging works by acquiring a reduced amount of $k$-space data with an array of receiver coils. Research is underway to see if it can provide equivalent information to the current gold-standard MRI [68, 69].

18 F-Fluorodeoxyglucose (FDG) positron emission tomography (PET) is a nuclear imaging modality that identifies increased glucose uptake in tissues. FDG-PET can be fused with MRI to improve the identification of high-grade features in gliomas [70].

Children with brain tumours are at risk for a number of late psychological effects, including neurocognitive and social deficits. These can be assessed with psychological questionnaires [16]. all included trials would allow OPGs as part of their criteria, but we cannot be sure that they will eventually recruit patients with this pathology in representative numbers, or if they will examine the data adequately to allow subgroup analysis of this pathology.

\section{Conclusion}

OPG are a debilitating childhood cancer that causes a significant burden of suffering. Our understanding of this disease is limited and we lack effective treatments and clear 
management consensus $[1,25]$. This manuscript details a systematic review of current ongoing trials in OPG. We find that from an initial yield of 501 hits, 36 ongoing trials fulfilled criteria for inclusion. The majority of these are studies or pharmacological agents, mostly phase I or II. OPG is a complex multifaceted disease, and advances in care are likely to require ongoing research efforts across a spectrum of different research fields [26]. Studies investigating surgical interventions and quality of life were notably absent. This review provides an update on the current state of research in OPG and highlights the main agents under investigation. We hope that this updates and stimulates clinicians and research scientists to engage with this important topic.

Acknowledgements Ciaran S. Hill is supported by a National Institute for Health Research Academic Clinical Lectureship, an Academy of Medical Science Grant, and a Cancer Research UK Pioneer Award.

\section{Compliance with ethical standards}

Conflict of interest The authors declare that they have no conflicts of interest.

Open Access This article is licensed under a Creative Commons Attribution 4.0 International License, which permits use, sharing, adaptation, distribution and reproduction in any medium or format, as long as you give appropriate credit to the original author(s) and the source, provide a link to the Creative Commons licence, and indicate if changes were made. The images or other third party material in this article are included in the article's Creative Commons licence, unless indicated otherwise in a credit line to the material. If material is not included in the article's Creative Commons licence and your intended use is not permitted by statutory regulation or exceeds the permitted use, you will need to obtain permission directly from the copyright holder. To view a copy of this licence, visit http://creativecommons.org/licenses/by/4.0/.

\section{References}

1. Binning MJ, Liu JK, Kestle JRW, Brockmeyer DL, Walker ML (2007) Optic pathway gliomas: a review. Neurosurg Focus 23:E2

2. Helfferich J, Nijmeijer R, Brouwer OF et al (2016) Neurofibromatosis type 1 associated low grade gliomas: a comparison with sporadic low grade gliomas. Crit Rev Oncol Hematol 104:30-41

3. Aquilina K, Daniels DJ, Spoudeas H, Phipps K, Gan HW, Boop FA (2015) Optic pathway glioma in children: does visual deficit correlate with radiology in focal exophytic lesions. Childs Nerv Syst 31: 2041-2049

4. Thomas RP, Gibbs IC, Xu LW et al (2015) Treatment options for optic pathway gliomas. Curr Treat Options Neurol 17:333

5. Calixto NC, Simão GN, Dos Santos AC et al (2019) Monitoring optic chiasmatic-hypothalamic glioma volumetric changes by MRI in children under clinical surveillance or chemotherapy. Childs Nerv Syst 35:63-72

6. Awdeh RM, Kiehna EN, Drewry RD, Kerr NC, Haik BG, Wu S, Xiong X, Merchant TE (2012) Visual outcomes in pediatric optic pathway glioma after conformal radiation therapy. Int J Radiat Oncol Biol Phys 84:46-51
7. Tsang DS, Murphy ES, Merchant TE (2017) Radiation therapy for optic pathway and hypothalamic low-grade gliomas in children. Int J Radiat Oncol Biol Phys 99:642-651

8. Sawamura Y, Kamada K, Kamoshima Y, Yamaguchi S, Tajima T, Tsubaki J, Fujimaki T (2008) Role of surgery for optic pathway/ hypothalamic astrocytomas in children. Neuro-Oncology 10:725733

9. Goodden J, Pizer B, Pettorini B, Williams D, Blair J, Didi M, Thorp $\mathrm{N}$, Mallucci C (2014) The role of surgery in optic pathway/ hypothalamic gliomas in children. J Neurosurg Pediatr 13:1-12

10. Gan H-W, Phipps K, Aquilina K, Gaze MN, Hayward R, Spoudeas HA (2015) Neuroendocrine morbidity after pediatric optic gliomas: a longitudinal analysis of 166 children over 30 years. J Clin Endocrinol Metab 100:3787-3799

11. Robert-Boire V, Rosca L, Samson Y, Ospina LH, Perreault S (2017) Clinical presentation and outcome of patients with optic pathway glioma. Pediatr Neurol 75:55-60

12. Rasool N, Odel JG, Kazim M (2017) Optic pathway glioma of childhood. Curr Opin Ophthalmol 28:289-295

13. Hidalgo ET, Kvint S, Orillac $\mathrm{C}$ et al (2019) Long-term clinical and visual outcomes after surgical resection of pediatric pilocytic/ pilomyxoid optic pathway gliomas. J Neurosurg Pediatr 1:1-8

14. Y-y L, Y-t L, Hu Q-1 et al (2019) Prognostic impact of neutrophilto-lymphocyte ratio in gliomas: a systematic review and meta-analysis. World J Surg Oncol 17:152

15. Taddei M, Erbetta A, Esposito S et al (2019) Brain tumors in NF1 children: influence on neurocognitive and behavioral outcome. Cancers (Basel) 11(11):1772

16. Papini C, Dineen RA, Walker DA et al (2020) Neuropsychological outcomes of children with optic pathway glioma. Sci Rep 10:1-10

17. Moher D, Liberati A, Tetzlaff J, Altman DG, PRISMA Group (2009) Preferred reporting items for systematic reviews and metaanalyses: the PRISMA statement. Ann Intern Med 151:264-269

18. Tricco AC, Lillie E, Zarin W, O'Brien KK, Colquhoun H, Levac D, Moher D, Peters MDJ, Horsley T, Weeks L, Hempel S, Akl EA, Chang C, McGowan J, Stewart L, Hartling L, Aldcroft A, Wilson MG, Garritty C, Lewin S, Godfrey CM, Macdonald MT, Langlois EV, Soares-Weiser K, Moriarty J, Clifford T, Tunçalp Ö, Straus SE (2018) PRISMA extension for scoping reviews (PRISMA-ScR): checklist and explanation. Ann Intern Med 169:467-473

19. Zaghloul MS (2016) Single pediatric neuro-oncology center may make difference in low/middle-income countries. Childs Nerv Syst 32:241-242

20. Chan MH, Boop F, Qaddoumi I (2015) Challenges and opportunities to advance pediatric neuro-oncology care in the developing world. Childs Nerv Syst 31:1227-1237

21. Hessissen L, Parkes J, Amayiri N, Mushtaq N, Sirachainan N, Anacak Y, Mitra D, Figaji A, Schouten-van Meeteren A, Sullivan M, Burger H, Davidson A, Bouffet E, Bailey S (2017) SIOP PODC adapted treatment guidelines for low grade gliomas in low and middle income settings. Pediatr Blood Cancer 64:e26737

22. Listernick R, Ferner RE, Liu GT, Gutmann DH (2007) Optic pathway gliomas in neurofibromatosis-1: controversies and recommendations. Ann Neurol 61:189-198

23. Shamji MF, Benoit BG (2007) Syndromic and sporadic pediatric optic pathway gliomas: review of clinical and histopathological differences and treatment implications. Neurosurg Focus 23:E3

24. de Blank PMK, Fisher MJ, Liu GT et al (2017) Optic pathway gliomas in neurofibromatosis type 1: an update: surveillance, treatment indications, and biomarkers of vision. J Neuroophthalmol 37(Suppl 1):S23-S32

25. Chan M-Y, Foong AP, Heisey DM, Harkness W, Hayward R, Michalski A (1998) Potential prognostic factors of relapse-free survival in childhood optic pathway glioma: a multivariate analysis. Pediatr Neurosurg 29:23-28 
26. Laithier V, Grill J, Le Deley M-C et al (2003) Progression-free survival in children with optic pathway tumors: dependence on age and the quality of the response to chemotherapy-results of the first French prospective study for the French Society of Pediatric Oncology. J Clin Oncol 21:4572-4578

27. Sullivan RJ, Infante JR, Janku F, Wong DJL, Sosman JA, Keedy V, Patel MR, Shapiro GI, Mier JW, Tolcher AW, Wang-Gillam A, Sznol M, Flaherty K, Buchbinder E, Carvajal RD, Varghese AM, Lacouture ME, Ribas A, Patel SP, DeCrescenzo GA, Emery CM, Groover AL, Saha S, Varterasian M, Welsch DJ, Hyman DM, Li BT (2018) First-in-class ERK1/2 inhibitor ulixertinib (BVD-523) in patients with MAPK mutant advanced solid tumors: results of a phase I dose-escalation and expansion study. Cancer Discov 8: 184-195

28. Schreck KC, Grossman SA, Pratilas CA (2019) BRAF mutations and the utility of RAF and MEK inhibitors in primary brain tumors. Cancers 11:1262

29. Sanchez JN, Wang T, Cohen MS (2018) BRAF and MEK inhibitors: use and resistance in BRAF-mutated cancers. Drugs. 78:549566

30. Del Bufalo F, Ceglie G, Cacchione A et al (2018) BRAF V600E inhibitor (Vemurafenib) for BRAF V600E mutated low grade gliomas. Front Oncol 8:526

31. Wright JD, Zimmerman MA, Fine E, Aspri T et al (2018) Type 2 II BRAF inhibitor TAK-580 shows promise for upcoming clinical trial as evidenced by single patient IND study. Neuro-oncology 20:i110

32. Kaul A, Toonen JA, Cimino PJ, Gianino SM, Gutmann DH (2015) Akt- or MEK-mediated mTOR inhibition suppresses Nfl optic glioma growth. Neuro-Oncology 17:843-853

33. Dombi E, Baldwin A, Marcus LJ et al (2016) Activity of selumetinib in neurofibromatosis type 1-related plexiform neurofibromas. N Engl J Med 375:2550-2560

34. Fangusaro J, Onar-Thomas A, Young Poussaint T, Wu S, Ligon AH, Lindeman N, Banerjee A, Packer RJ, Kilburn LB, Goldman S, Pollack IF, Qaddoumi I, Jakacki RI, Fisher PG, Dhall G, Baxter P, Kreissman SG, Stewart CF, Jones DTW, Pfister SM, Vezina G, Stern JS, Panigrahy A, Patay Z, Tamrazi B, Jones JY, Haque SS, Enterline DS, Cha S, Fisher MJ, Doyle LA, Smith M, Dunkel IJ, Fouladi M (2019) Selumetinib in paediatric patients with BRAFaberrant or neurofibromatosis type 1-associated recurrent, refractory, or progressive low-grade glioma: a multicentre, phase 2 trial. Lancet Oncol 20:1011-1022

35. Avery RA, Hwang EI, Jakacki RI, Packer RJ (2014) Marked recovery of vision in children with optic pathway gliomas treated with bevacizumab. JAMA Ophthalmol 132:111-114

36. Wu WS, Liu JJ, Sun YL et al (2019) Effect of bevacizumab in treatment of children with optic pathway glioma. Zhongguo Dang Dai Er Ke Za Zhi 21:1193

37. Zhukova N, Rajagopal R, Lam A, Coleman L, Shipman P, Walwyn T, Williams M, Sullivan M, Campbell M, Bhatia K, Gottardo NG, Hansford JR (2019) Use of bevacizumab as a single agent or in adjunct with traditional chemotherapy regimens in children with unresectable or progressive low-grade glioma. Cancer Med 8:4050

38. Yamasaki F, Takano M, Yonezawa U, Taguchi A, Kolakshyapati M, Okumichi H, Kiuchi Y, Kurisu K (2020) Bevacizumab for optic pathway glioma with worsening visual field in absence of imaging progression: 2 case reports and literature review. Childs Nerv Syst 36:635-639

39. Capozzi M, De Divitiis C, Ottaiano A et al (2019) Lenvatinib, a molecule with versatile application: from preclinical evidence to future development in anti-cancer treatment. Cancer Manag Res $11: 3847-3860$
40. Rajkumar SV, Witzig TE (2000) A review of angiogenesis and antiangiogenic therapy with thalidomide in multiple myeloma. Cancer Treat Rev 26:351-362

41. Hassler MR, Sax C, Flechl B, Ackerl M, Preusser M, Hainfellner JA, Woehrer A, Dieckmann KU, Rössler K, Prayer D, Marosi C (2015) Thalidomide as palliative treatment in patients with advanced secondary glioblastoma. Oncology 88:173-179

42. Fine HA, Kim L, Albert PS, Duic JP, Ma H, Zhang W, Tohnya T, Figg WD, Royce C (2007) A phase I trial of lenalidomide in patients with recurrent primary central nervous system tumors. Clin Cancer Res 13:7101-7106

43. Drappatz J, Wong ET, Schiff D et al (2009) A pilot safety study of lenalidomide and radiotherapy for patients with newly diagnosed glioblastoma multiforme. Int J Radiat Oncol Biol Phys 73:222-227

44. Warren KE, Goldman S, Pollack IF, Fangusaro J, Schaiquevich P, Stewart CF, Wallace D, Blaney SM, Packer R, MacDonald T, Jakacki R, Boyett JM, Kun LE (2011) Phase I trial of lenalidomide in pediatric patients with recurrent, refractory, or progressive primary CNS tumors: Pediatric Brain Tumor Consortium study PBTC-018. J Clin Oncol 29:324-329

45. Moore CA, Ibrahim M, Kapila A et al (2018) Glioblastoma multiforme in a patient with multiple myeloma: a case report and literature review. Perm J 22:17-125

46. Fangusaro JR, Locatelli F, Garré ML et al (2019) A phase II clinical study of pomalidomide (CC-4047) monotherapy for children and young adults with recurrent or progressive primary brain tumors

47. Mukhopadhyay T, Sasaki J, Ramesh R et al (2002) Mebendazole elicits a potent antitumor effect on human cancer cell lines both in vitro and in vivo. Clin Cancer Res 8:2963-2969

48. Bai RY, Staedtke V, Aprhys CM, Gallia GL, Riggins GJ (2011) Antiparasitic mebendazole shows survival benefit in 2 preclinical models of glioblastoma multiforme. Neuro-Oncology 13:974-982

49. Purow B (2016) Repurposing existing agents as adjunct therapies for glioblastoma. Neuro-Oncol Pract 3:154-163

50. Guerini AE, Triggiani L, Maddalo M et al (2019) Mebendazole as a candidate for drug repurposing in oncology: an extensive review of current literature. Cancers (Basel) 11(9):1284

51. Eyüpoglu IY, Hahnen E, Tränkle C, Savaskan NE, Siebzehnrübl FA, Buslei R, Lemke D, Wick W, Fahlbusch R, Blümcke I (2006) Experimental therapy of malignant gliomas using the inhibitor of histone deacetylase MS-275. Mol Cancer Ther 5:1248-1255

52. Lee P, Murphy B, Miller R et al (2015) Mechanisms and clinical significance of histone deacetylase inhibitors: epigenetic glioblastoma therapy. Anticancer Res 35:615-625

53. Warren K, Bent R, Wolters PL, Prager A, Hanson R, Packer R, Shih J, Camphausen K (2012) A phase 2 study of pegylated interferon $\alpha$ $2 \mathrm{~b}$ (PEG-Intron $\left.{ }^{\circledR}\right)$ in children with diffuse intrinsic pontine glioma. Cancer 118:3607-3613

54. Lubanska D, Porter L (2017) Revisiting CDK inhibitors for treatment of glioblastoma multiforme. Drugs R D 17:255-263

55. Weyerhäuser P, Kantelhardt SR, Kim EL (2018) Re-purposing chloroquine for glioblastoma: potential merits and confounding variables. Front Oncol 8:335

56. Krueger DA, Care MM, Holland K et al (2010) Everolimus for subependymal giant-cell astrocytomas in tuberous sclerosis. $\mathrm{N}$ Engl J Med 363:1801-1811

57. MacKeigan JP, Krueger DA (2015) Differentiating the mTOR inhibitors everolimus and sirolimus in the treatment of tuberous sclerosis complex. Neuro-Oncology 17:1550-1559

58. Kyi C, Roudko V, Sabado R et al (2018) Therapeutic immune modulation against solid cancers with intratumoral poly-ICLC: a pilot trial. Clin Cancer Res 24:4937-4948

59. Fulci G, Breymann L, Gianni D, Kurozomi K, Rhee SS, Yu J, Kaur B, Louis DN, Weissleder R, Caligiuri MA, Chiocca EA (2006) Cyclophosphamide enhances glioma virotherapy by inhibiting 
innate immune responses. Proc Natl Acad Sci U S A 103:1287312878

60. Wolff JE, Wagner S, Reinert C et al (2006) Maintenance treatment with interferon-gamma and low-dose cyclophosphamide for pediatric high-grade glioma. J Neuro-Oncol 79:315-321

61. Du B, Waxman DJ (2020) Medium dose intermittent cyclophosphamide induces immunogenic cell death and cancer cell autonomous type I interferon production in glioma models. Cancer Lett 470:170-180

62. Yamashita AS, da Costa RM, Borodovsky A et al (2019) Demethylation and epigenetic modification with 5-azacytidine reduces IDH1 mutant glioma growth in combination with temozolomide. Neuro-Oncology 21:189-200

63. Chiocca EA, Yu JS, Lukas RV et al (2019) Regulatable interleukin12 gene therapy in patients with recurrent high-grade glioma: results of a phase 1 trial. Sci Transl Med 11(505):eaaw5680

64. Majzner RG, Theruvath JL, Nellan A et al (2019) CAR T cells targeting B7-H3, a pan-cancer antigen, demonstrate potent preclinical activity against pediatric solid tumors and brain tumors. Clin Cancer Res 25:2560-2574

65. Huang B, Luo L, Wang J, He B, Feng R, Xian N, Zhang Q, Chen L, Huang G (2020) B7-H3 specific T cells with chimeric antigen receptor and decoy PD-1 receptors eradicate established solid human tumors in mouse models. Oncoimmunology 9:1684127

66. Salem U, Kumar VA, Madewell JE, Schomer DF, de Almeida Bastos DC, Zinn PO, Weinberg JS, Rao G, Prabhu SS, Colen RR (2019) Neurosurgical applications of MRI guided laser interstitial thermal therapy (LITT). Cancer Imaging 19:65

67. Shen L, Zhang J, Lee H, Batista MT, Johnston SA (2019) RNA transcription and splicing errors as a source of cancer frameshift neoantigens for vaccines. Sci Rep 9:14184

68. Bilgic B, Gagoski BA, Cauley SF et al (2015) Wave-CAIPI for highly accelerated 3D imaging. Magn Reson Med 73:2152-2162

69. Conklin J, Longo MGF, Cauley SF et al (2019) Validation of highly accelerated wave-CAIPI SWI compared with conventional SWI and $\mathrm{T} 2 *$-weighted gradient recalled-echo for routine clinical brain MRI at 3T. AJNR Am J Neuroradiol 40:2073-2080

70. Shaw TB, Jeffree RL, Thomas P, Goodman S, Debowski M, Lwin Z, Chua B (2019) Diagnostic performance of $18 \mathrm{~F}$ fluorodeoxyglucose positron emission tomography in the evaluation of glioma. J Med Imaging Radiat Oncol 63:650-656

Publisher's note Springer Nature remains neutral with regard to jurisdictional claims in published maps and institutional affiliations. 